NBER WORKING PAPER SERIES

\title{
DOES HIGH COST-SHARING SLOW THE LONG-TERM GROWTH RATE OF HEALTH SPENDING? EVIDENCE FROM THE STATES
}

\author{
Molly Frean \\ Mark Pauly \\ Working Paper 25156 \\ http://www.nber.org/papers/w25156 \\ NATIONAL BUREAU OF ECONOMIC RESEARCH \\ 1050 Massachusetts Avenue \\ Cambridge, MA 02138
}

October 2018, Revised September 2019

We thank Claudio Lucarelli and Sarah Dykstra for thoughtful comments and suggestions. The views expressed herein are those of the authors and do not necessarily reflect the views of the National Bureau of Economic Research.

NBER working papers are circulated for discussion and comment purposes. They have not been peerreviewed or been subject to the review by the NBER Board of Directors that accompanies official NBER publications.

(C) 2018 by Molly Frean and Mark Pauly. All rights reserved. Short sections of text, not to exceed two paragraphs, may be quoted without explicit permission provided that full credit, including $\odot$ notice, is given to the source. 
Does High Cost-Sharing Slow the Long-term Growth Rate of Health Spending? Evidence from the States

Molly Frean and Mark Pauly

NBER Working Paper No. 25156

October 2018, Revised September 2019

JEL No. I11,I13

\begin{abstract}
Research has shown that higher cost-sharing lowers health care spending levels but less is known about whether cost-sharing also affects spending growth. From 2002 to 2016, private insurance deductibles more than tripled in magnitude. We use data from the Centers for Medicare and Medicaid Services and the Agency for Healthcare Research and Quality to estimate whether areas with relatively higher deductibles experienced lower spending growth during this period. We leverage panel variation in private deductibles across states and over time and address the potential endogeneity of deductibles using instrumental variables. We find that spending growth is significantly lower in states with higher average deductibles and observe this relationship with regard to both private insurance benefits and total spending (including Medicare and Medicaid), suggestive of potential spillovers. We hypothesize that the impact on spending growth happens because deductibles affect the diffusion of costly new technology.
\end{abstract}

\author{
Molly Frean \\ The Wharton School \\ University of Pennsylvania \\ 3641 Locust Walk \\ Philadelphia, PA 19104 \\ United States \\ mfrean@wharton.upenn.edu \\ Mark Pauly \\ Health Care Management Department \\ The Wharton School \\ University of Pennsylvania \\ 208 Colonial Penn Center \\ 3641 Locust Walk \\ Philadelphia, PA 19104-6218 \\ and NBER \\ pauly@wharton.upenn.edu
}




\section{Introduction}

Many studies of health insurance establish a positive relationship between the level of coverage and spending, consistent with the theory of moral hazard and also accessibility arguments. (Pauly, 1968; Nyman, 1999). Early empirical work considered overall coinsurance rates, followed by studies of the presence or absence of Medicare and Medicaid coverage (Manning et al., 1987; Finkelstein, 2007; Finkelstein et al., 2012). More recently and in response to their growing prevalence, research has shown that high deductibles also reduce spending levels (Bundorf, 2016; Haviland et al., 2016; Brot-Goldberg et al., 2017). This reduction in spending has been tracked over at most three additional years (Haviland et al., 2016). However, evidence on what happens to spending growth for populations with longer-term persistence of high cost-sharing plans is limited, and no one knows whether such insurance can bend the cost curve for an extended period. To the extent that the adoption and diffusion of beneficial but costly new technology is the primary driver of spending growth, the potential impact of insurance coverage on that choice is of primary interest.

Long-term spending growth has primarily been explored using nationally aggregated time series data, comparing growth in national health expenditures (NHE) or personal health expenditures (PHE) to the population's average level of out of pocket spending (Newhouse, 1978, 1988, 1992, 1993; Peden and Freeland, 1998). These older analyses concern forms of cost-sharing that have been eclipsed by others (namely, the increasingly popular high deductible health plan [HDHP]), and their statistical power is limited by the necessarily small number of time series observations with nationally aggregated data. A more recent study using national Medicare data found that supplemental coverage was associated with significantly higher spending growth, further motivating research on this topic (Golberstein et al., 2013).

In this paper, we leverage panel variation across states and over time in the proportion of privately insured employees covered by plans with high versus lower deductibles. We relate variation in states' average deductibles to the growth of private health spending, and also to total health care spending (across all payers), thus capturing any spillover effects of changes in plan generosity for a large segment of the population on spending growth for the entire United States population. We find that current period medical spending growth for the privately insured is significantly lower 
in states with higher deductible levels than in those with lower levels. In contrast, and consistent with work by Peden and Freeland (henceforth PF), we do not find a significant negative effect of changes in deductibles on contemporaneous spending growth. We also find evidence of potential spillovers to individuals insured via public programs (i.e. Medicare and Medicaid). These findings are robust despite the absence of a positive correlation between the level of high-deductible insurance penetration and the rate of growth in that penetration, and the lack of a correlation between the level of spending and the rate of growth of spending.

\section{Theory}

In this section, we review how economic theory can guide predictions regarding the relationship between health insurance deductibles and both spending levels and spending growth. Other work has modeled optimal deductible levels and the individual's choice of deductible (Keeler et al., 1977; Parente et al., 2004b). While our focus is on deductibles, the insights apply to other measures of coverage generosity such as coinsurance rates and copayments. We also abstract away from the possible relevance of behavioral economics to insurance choices and actions under insurance, as well as the role of liquidity constraints and tax-shielded savings accounts that often accompany high deductible plans. However, we acknowledge that a complete model of deductibles and health care spending should take such considerations into account.

\section{Deductibles and Spending Levels}

It is well established that, at the individual- or insurance plan-level, raising out of pocket (OOP) payments (e.g., by increasing an annual deductible) will lower spending levels for a time period or two after the change. Empirical studies often compare a single population before and after a switch to a high deductible or compare a high deductible treatment group to a lower-deductible control group. This finding of lower spending after switching to a HDHP is consistent with the theory of moral hazard: a higher average user price of care reduces the quantity of care demanded (Pauly, 1968). This prediction and this analysis are simplest under the assumption that the set of services available (i.e., technology) is constant over time. To see this, consider the following example. 
Assume that an individual's annual medical expenses are a non-negative random variable $X$ with distribution in the population characterized by $f(X)$ and $F(X)$. Consider a plan that provides full insurance above an initial deductible $D$. The plan's expected benefits per member are given by:

$$
\mathbb{E}[X-D \mid X>D]=\frac{\int_{D}^{\infty}(x-D) f(x) d x}{1-F(D)}
$$

Ignoring effects of aging and other factors, further assume that the distribution of medical expenses $X$ in the population remains the same between years. A natural test of a moral hazard response to a higher deductible is whether expected benefits fall by more than what would be expected given the equation above.

\section{Deductibles and Spending Growth}

Evidence on spending growth in the United States (US) and in all other countries is consistent with the accounting identity: growth is composed of changes in unit prices and changes in quantity. There is a consensus in the literature that the primary driver of health care spending growth is technology growth, which can result in a net increase in average prices, quantities or both (Weisbrod, 1991; Chandra and Skinner, 2012). Hence, any relationship between insurance coverage and spending growth depends on whether the level of coverage affects the diffusion of new technology and/or the rate of growth in unit prices a point we consider below. Before proceeding, it is also important to note that technology itself is not wholly exogenous and may be endogenous to changes in insurance, as well as to changes in income levels or tastes.

It is plausible, but so far unproven, that higher patient cost-cost sharing (e.g. in the form of higher deductibles) will discourage the use of new and beneficial but incrementally costly new technologies, or that the extent of use depends on the level and distribution of value-added by that technology (versus the so-called "supply imperative"). It is less clear whether there should be a relationship between insurance coverage and growth in average prices, independent of technological advances. While increasing rates of provider consolidation are often behind rising prices, it is not obvious how changes in the generosity of coverage should affect such consolidation. Perhaps more interesting is the possibility that higher cost-sharing will increase the average consumer's demand elasticity 
and thus deter price increases in response to increases in marginal cost. However a recent study of employees switched to a high deductible plan found no evidence of increased price shopping, which weakens provider incentives to lower prices in the face of insurance changes that expose patients to a greater share of such prices (Brot-Goldberg et al., 2017). Going forward, we assume in our model that prices and price changes across sates are exogenous so that spending growth proxies greater use of technology.

Figure 1 shows a hypothetical pattern of spending growth before and after a coverage change at $t=0$ that exposes patients to greater cost-sharing (e.g. a switch from a low to a high deductible plan). We treat the introduction of new technology as both exogenous and constant over time. The solid lines show two alternative time paths of total spending, while the bottom dashed line shows the incremental spending on new technology each period. Suppose the coverage change reduces the incremental spending on new technology by half, as shown. Alone, this effect would cause a kink in the total spending line, as reflected in the green continuation of the total spending line after $t=0$. If the coverage change also reduces spending on existing services (potentially those that are lower value), total spending would instead track the blue line after $t=0$, which reflects a level effect in addition to a slope effect.

\section{Data}

\section{Private Insurance Deductibles and Premiums}

Our primary data source for data on private insurance coverage is the Medical Expenditure Panel Survey (MEPS). The MEPS is a national, annual, large-scale survey administered by the Agency for Healthcare Research and Quality (AHRQ). It includes two major and separate components: the household component (HC) and the insurance component (IC). The HC collects data from families and individuals across the country on their health care utilization and costs, while the IC collects data from about 40,000 public and private sector employers on the health benefits offered to employees.

For this study, we use the 2002-2016 MEPS IC and focus on those data provided by privatesector employers only. Data were not collected for the MEPS IC in 2007, so we impute such 
data with means of 2006 and 2008 values for relevant variables. We construct measures of average premiums and deductibles by state-year using national enrollment-weighted means of such measures for single-person and family coverage. In the case of deductibles, we construct both conditional and unconditional averages. The conditional measure is the average deductible among those with a positive deductible; the unconditional measure multiplies that by the proportion of individuals with a positive deductible. The unconditional average deductible is our preferred summary measure of private insurance generosity for a given state-year. Deductible measures are used as our primary independent variables, while premium measures are used as dependent measures of private health insurance benefits.

Figure 2 shows trends in deductibles from 2002 to 2016. Over this time period, conditional deductibles for single coverage increased from $\$ 575$ to $\$ 1,662$ and conditional deductibles for family coverage increased from $\$ 1,235$ to $\$ 3,073$. Of note, though not shown in the figure, the proportion of employees with a positive deductible increased from $52 \%$ to $88 \%$. Thus, the unconditional average deductible increased from $\$ 458$ to $\$ 1,885$. For reference, a deductible is considered "high" when it exceeds $\$ 1,000$ for single coverage and $\$ 2,000$ for family coverage (Kaiser Family Foundation, 2014).

\section{Health Care Spending}

For data on health care spending, we rely on the State Health Expenditure Accounts (SHEA), an extension of the National Health Expenditure Accounts (NHEA), which are maintained by the US Centers for Medicare and Medicaid Services (CMS) and considered to be the official estimates of total health care spending in the country. The 1991-2014 SHEA are publicly available and can be found online along with detailed documentation of the methodology behind the data. The SHEA are estimated at the "Personal Health Care (PHC)" level and capture the consumption of all health care goods and services in all states across the country. Administrative costs associated with insurance provision, public health activities, and health investment funds are excluded. The SHEA estimates of PHC spending are available at the aggregate state level, representing total health care spending financed by all sources (insured and out-of-pocket), and also by payer (Private, Medicare, Medicaid) and service setting (e.g. hospital care, physician services, prescription drugs). While the 
estimates of spending by setting reflect spending financed by all sources, payer-specific estimates reflect benefits only and exclude out-of-pocket payments by the insured. Of note, private health insurance (PHI) expenditures in the SHEA are derived from information on premium payments, where net cost ratios $^{1}$ are applied to derive PHI benefits. As the SHEA do not contain a separate measure of the insured's OOP spending, we are unable to analyze total spending on insured services (private nor public).

For the purposes of this study, we utilized the 2002-2014 SHEA. Figure 3 shows trends in spending per capita over this time period: Panel A shows total spending and spending on benefits by payer, and Panel B shows total spending in selected settings. With the exception of Medicaid, all spending measures increased considerably over the data window, with the greatest growth observed in hospital spending (47\%) and PHI spending (44\%).

\section{Other}

In addition to the MEPS IC and the SHEA, we drew upon several other public data sources for model covariates and instruments (described in more detail in a later section). We used the US Census Bureau's Current Population Survey (CPS) for data on health insurance coverage rates and employment. The CPS health insurance questions were redesigned in 2013 and the Census Bureau advises against combining both versions of the data. Due to this limitation, models with controls from the CPS only use data from 2002-2012. To further characterize health care markets across states, we used data from CMS on each state's market penetration of Medicare Advantage (the managed care alternative to traditional fee-for-service Medicare) and used data from the American Hospital Association (AHA) annual surveys to characterize concentration of a state's hospital markets. For the latter, we first constructed a Herfindahl-Hirschman Index for each core-based statistical area (CBSA) in a state and then took a market-size-weighted average of the indices for each state in a given year. Finally, we used data from the National Conference of State Legislatures (NCSL) on the republican share of state legislature seats.

\footnotetext{
${ }^{1}$ Net costs include administrative expenses, changes in reserves, and profit margins.
} 


\section{Measure and Sample Construction}

All dollar measures (spending, deductibles, and premiums) were adjusted for inflation using the Gross Domestic Product (GDP) index from the Bureau of Economic Analysis, a part of the US Department of Commerce, and are reported here in 2014 US Dollars.

We elected to create two groups of small states (with populations below 1 million) for purposes of analysis. We combined Delaware, the District of Columbia and Vermont into an eastern group, and North Dakota, South Dakota and Wyoming into a western group. For each group, we generated weighted averages of study measures with weights based on the relative size of the state's employee population in the MEPS IC each year. We also excluded Alaska due to the large share of government spending on behalf of the state's Native American population. This results in a total of 46 observations per data year (44 states plus two state groups), with the exception of the 2002 MEPS IC, where the sample size is 43 due to missing data for a subset of states. ${ }^{2}$

\section{Empirical Strategy}

\section{Regression Model}

We begin with a simple model of health care spending in state i in year $\mathrm{t}$, denoted Yit:

$$
Y_{i t}=\alpha+\beta X_{1 i t}+\gamma Z_{i}+\lambda T+\delta\left(T \times X_{2 i t}\right)
$$

Above, $X_{1 i t}$ is a vector of state- and time-varying determinants of spending levels, $Z_{i}$ is a vector of state-varying spending determinants that are constant over time, and $T$ is a linear time trend. We interact the time trend with a second vector, $X_{2 i t}$, which includes state- and time-varying determinants of spending growth (Golberstein et al., 2013). Note that $X_{1 i t}$ and $X_{2 i t}$ may share some elements, but not others, depending on whether theory predicts a relationship with spending levels, spending growth, or both. We hypothesize that average private group insurance deductibles

\footnotetext{
${ }^{2}$ The 2002 MEPS IC has missing data for eight states: AK, AR, DC, ID, ND, RI, SD, and VT. Missing data for Alaska is irrelevant as the state is dropped from all analyses. Four other states (DC, ND, SD, and VT) are in groups with another state with non-missing data, which is used to represent the entire group for 2002. Thus, we effectively lose three observations from the ideal 46 (AR, ID and RI).
} 
affect both spending levels and growth, and thus consider them a part of both $X_{1 i t}$ and $X_{2 i t}$. We choose this simple functional form for convenience and note that it need not reflect an exact specification of the relationships between the explanatory variables and health care spending.

Differencing Equation (1) with respect to time and rearranging yields the alternative specification we use:

$$
\Delta Y_{i t}=\lambda+\delta X_{2 i t}+\beta \Delta X_{1 i t}
$$

Note that either specification should give rise to the same estimates of the coefficients of interest

$\lambda, \beta$, and $\delta$. One advantage of estimating Equation (2) over Equation (1) is that it is not necessary to control for spending determinants in $Z_{i}$ that only affect the time-independent level of spending and not its growth.

We are interested in the relationship between one element of $X_{1 i t}$ and $X_{2 i t}$ - the average deductible among privately insured employees in a state - and spending growth. A simplified version of Equation (2) replaces $X_{1 i t}$ and $X_{2 i t}$ with such a measure, denoted $D_{i t}$ :

$$
\Delta Y_{i t}=\lambda+\delta D_{i t}+\beta \Delta D_{i t}
$$

It is possible to estimate Equation (3) and obtain unbiased estimates of $\beta$ and $\delta$ if and only if Dit is exogenous. We address this issue below.

\section{Identification}

Estimation of Equation (3) with market-level data (as in an entire state) has several identification advantages over other datasets. A primary concern with estimating Equation (3) with individuallevel data would be that spending differences across plan types will reflect, at least to some degree, adverse selection where those who are high risk prefer more generous coverage (e.g. lower deductibles) and vice versa. However, estimating Equation (3) with state-level data should reflect the overall "intent to treat" effect of rising average deductibles among all privately insured employees whatever plan they choose. This will be the case unless a state's average deductible is related to a larger fraction of employees being high or low risk (compared to other states) and 
employers responding to this by offering lower or higher deductible plans, respectively. However, because employment-based insurance is largely experience-rated or self-insured at the firm level, the conventional cross-sectional adverse selection model does not apply. Theory does not predict with certainty that lower risks will prefer higher deductible plans. Estimating Equation (3) with national time-series data would also be imperfect to the extent that expectations about future insurance or cost-sharing levels in the population influence industry research and development investment in new technology. With state-level data, this potential problem is minimized since providers nationwide presumably have the same access to current technology, even when average deductibles vary across states.

While our state-level data attenuate the issues described above, deductibles may still be endogenous. A natural concern is the omission of other state- and time-varying variables that directly affect health care spending and are correlated with deductibles. Such variables may include a state's uninsured rate, managed care penetration (and with it, supply-side cost controls) and other measures of coverage generosity, such as coinsurance rates and out-of-pocket maximums. Other variables that certainly affect spending include average income, other population demographics, medical price inflation and provider consolidation, though their relationships with deductibles are less clear a priori.

It is also important to consider whether causality might flow in the opposite direction. For example, one might consider the adoption of higher deductibles by payers, employers or consumers to be a rational response to high spending growth (e.g. due to increased provider consolidation). This would manifest as a positive relationship between average deductible levels and spending growth, which is the opposite sign to our hypothesis and to what we observe in our data. We cannot conceive of a logical a priori reason for the adoption of higher deductibles in response to lower spending growth in a market, but we cannot rule this out as absolutely impossible.

We address potential endogeneity bias arising from omitted variables and/or reverse causality in two ways. First, we estimate Equation (3) with both ordinary least squares (OLS) and two-stage least squares (2SLS). Second, we estimate both sets of models OLS and 2SLS incorporating time-varying controls as well as state fixed effects. We include as controls insurance coverage 
rates (uninsured, privately insured, Medicare and Medicaid), Medicare Advantage penetration (as a measure of general managed care penetration), and hospital market concentration. We do not use a state's average income per capita as a control because higher cost-sharing (and associated lower employer premiums) tends to increase money wages, making income endogenous. ${ }^{3}$ We include both levels of and changes in each control variable, as we do with the average unconditional deductible. We do not use the above controls in our primary specification because the sample size is reduced with the insurance controls and because ex ante relationships with deductibles are not definitive.

In the 2SLS models, we use four instrumental variables (IV) that predict average deductibles across states and over time and are arguably exogenous to spending growth (even if not exogenous to spending levels). First, we use the average private firm size in the MEPS-IC, given that smaller firms are more likely to offer health plans with high deductibles (Kaiser Family Foundation, 2014). Second, we use the proportion of private sector workers that are unionized (available in the CPS), as unions traditionally negotiate more generous health insurance benefits (Buchmueller et al., 2002). As high deductibles began as a republican policy idea, we use as a third instrument the republican share of state legislature seats from the NCSL (The Heritage Foundation, 2006). ${ }^{4}$ Our fourth and final instrument is the mean age of adult civilian full-time workers, also available in the CPS. Worker age has been considered in prior work as a potentially relevant factor for deductible choice, and while age predicts spending levels at the individual level, we consider it exogenous to spending growth at the market level (Parente et al., 2004a; Van de Ven and Van Praag, 1981). First-stage results are included in Table 1. As expected, firm size and unionization bear a negative relationship with deductibles, and a higher republican share of the legislature predicts higher deductibles. Higher worker age also predicts higher deductibles (albeit with a lower magnitude), which we attribute to low deductibles being preferred by younger workers starting families. Together, the four instruments explain almost half of the variation in average deductibles in our data and the model is highly significant, as reflected by the $F$ statistic of 42.15 .

\footnotetext{
${ }^{3}$ The correlation between our average conditional deductible measure and income per capita (obtained from the Bureau of Economic Analysis) is moderately positive and significant $(r=0.354, p<0.01)$.

${ }^{4}$ This measure is missing for Nebraska given its unicameral legislature.
} 


\section{Estimation}

We use Stata 14 to estimate the model in Equation (3) using both OLS and 2SLS. For $\Delta Y_{i t}$, we consider growth in the SHEA spending measures and also growth in premiums for employersponsored coverage in the MEPS IC. In all cases, we measure growth as the percentage change since the previous year. We operationalize $D_{i t}$ with the logged average unconditional deductible and use the percent change in this deductible since the prior year for $\Delta D_{i t}$, unless otherwise indicated. All percent changes are calculated using the difference in natural logs. We test the sensitivity of our results to these analytic choices by estimating a set of models using absolute dollar changes instead of percent changes. In all models we utilize robust standard errors clustered by state to account for potential heteroscedasticity and intra-state correlations over time.

\section{Results}

\section{Growth in Total Health Care Spending and Private Benefits}

Table 2 includes results from models of growth in total health care spending per capita (Columns 1 and 2) and growth in private benefits per enrollee (Columns 3 and 4), with OLS and IV results presented side by side for each. The models of total spending are intended to replicate the PF analysis, while the models of private benefits reflect that spending which we expect to be most responsive to variation in our average deductible measure. For both outcomes, we observe a significant negative relationship between deductible levels and spending growth, with coefficient magnitudes remarkably similar between OLS and IV and higher in the models of private benefits. We observe a positive or non-significant relationship between the change in deductible and spending growth.

While the SHEA do not contain data on OOP spending by the privately insured, we constructed such a measure as follows: (1) estimate total OOP spending by subtracting total benefits (Private + Medicare + Medicaid) from total spending in SHEA; (2) obtain estimates of OOP spending per Medicare beneficiary and per uninsured person from MEPS HC; (3) estimate total OOP for Medicare beneficiaries and total OOP for the uninsured by multiplying estimates from previous step by number of Medicare beneficiaries and number of uninsured; and (4) estimate total OOP spending 
per privately insured as difference between total OOP in step (1) and OOP spending measures in step (3), divided by privately insured population. Results from models relating average deductibles to this estimated private OOP measure and to total spending on behalf of the privately insured are provided in Appendix Table A1. As in Table 1, a higher average deductible is associated with lower growth in these measures. Additionally, and intuitively, the change in the average deductible is significantly positively associated with growth in these measures.

\section{Growth in Total Spending for Selected Settings}

Table 3 disaggregates growth in total spending into growth in three settings: hospital care (Columns 1 and 2), physician services (Columns 3 and 4) and prescription drugs (Columns 5 and 6). As in Table 2, both OLS and IV results are presented for each setting. In all settings, higher deductible levels are associated with lower spending growth. In exploratory analyses, we find that the significant relationship with hospital spending growth is driven by lower growth in admissions per capita, rather than in spending per admission (see Appendix Table A2). The magnitude of the deductible level coefficient is highest for prescription drug spending, which may reflect more consumer discretion and/or a greater prevalence of new technology relative to other settings. Again, we observe positive or non-significant relationships between the change in deductible and spending growth.

\section{Spillovers to Spending in Public Programs}

There has been considerable interest in and evidence for the hypothesis that changes in determinants of care utilization under private insurance also affect utilization of those with other insurance. The primary channel for such effects is assumed to be physician behavior in which physicians prefer not to incur the cost (real and subjective) associated with treating patients with identical conditions differently because they have different insurance coverage. Changes in coverage for a sufficiently large share of the market may also affect hospital willingness to incur the fixed costs associated with adopting new practice styles (Finkelstein, 2007). In Table 4, we therefore present results for growth in Medicare and Medicaid benefits per enrollee. In these models, we again observe a significant negative relationship between deductible levels and spending growth, which may represent spillover effects from private deductibles to public spending. We also investigated 
whether or not the proportion privately insured via group coverage (among all insured) moderated the relationship between average deductible levels and public spending growth, however we did not find a large nor consistent effect. This may reflect relatively low variation across states and over time in the proportion with private group coverage.

\section{Summary of Spending Models}

Across Tables 1-4, a higher average deductible level consistently predicts lower spending growth, while the change in the average deductible does not have a consistent relationship with spending growth. The absence of a significant negative effect for the change in coverage generosity (as measured by deductibles), controlling for the level of that coverage, is consistent with the results of PF. Importantly, these results are generally robust to the inclusion of additional controls and state fixed effects (see Appendix Tables A3-A6). Results are also robust to an alternative specification that uses dollar changes (in spending and deductibles) and does not log-transform the average deductible level (see Appendix Tables A7 and A8).

\section{Private Premium Growth}

All else equal, a higher deductible will lower the actuarial value of benefits. If per capita premiums bear a proportional relationship to per capita benefits, reductions in the actuarial value of benefits should translate into proportional reductions in premiums. However, if an increase in deductibles reduces moral hazard, for which a portion of spending falls above the deductible, the level of total spending will fall even more. In this case, the fall in premiums should be greater than the fall in the actuarial value of benefits.

The results of regressions relating growth in private group insurance premiums per person (from the MEPS IC) to the levels and changes in unconditional deductibles are shown in Table 4. The first two columns use percent changes in premiums and deductibles while the second two columns use dollar changes. As in prior tables, OLS and IV results are presented side by side. In all four columns, the deductible level is negative and highly significant. Unlike in the spending models, all models in Table 4 also indicate a negative impact of the deductible change on premiums, though only the models with changes expressed in dollars achieve statistical significance. The coefficient 
on the change in deductible is not large enough relative to the change in actuarial value of benefits to indicate a moral hazard effect on current technology spending at the levels of deductible that commonly prevailed.

\section{Discussion}

Our results strongly confirm the main PF hypothesis that high levels of cost sharing, in this case in the form of deductibles, are associated with lower rates of spending growth. The findings are also consistent with the study of supplemental Medicare coverage mentioned earlier. However, an earlier study comparing spending growth between employees in alternative plans, including a HDHP, at a single employer found higher cost growth over three years in their HDHP group (Parente et al., 2004b). Our findings likely differ from theirs given our aggregate and longer-term approach. Prior work has shown that results often differ considerably at the aggregate level compared to the individual level (Finkelstein, 2007).

The magnitude of our estimates implies that annual growth in total spending per capita from 2002-2014 would have been approximately 0.86 percentage points higher had average deductibles prevailed at their 2002 levels. This finding is an interesting combination of static and dynamic behavior, in that the level of one variable affects the rate of change of another - but that is what our model of new and old technology implies. In contrast, the change in cost-sharing since the previous period does not have a consistently significant nor negative effect on spending growth. However, it does sometimes have the expected significant negative effect on the growth of private insurance benefits, though the magnitude is small. Given that the annual changes in deductibles were relatively modest during this period (about $11 \%$ per year on a base of about $\$ 1,120$ ), it is perhaps not surprising that we did not find a statistically significant effect of those changes on spending growth, consistent with existing perspectives in the literature (Peden and Freeland, 1998; Chernew and Newhouse, 2011). Moreover, the well-known RAND health insurance experiment showed that the bulk of the negative effects of higher cost-sharing on spending arise from moving from zero cost-sharing to relatively low levels of cost-sharing (Manning et al., 1987). This is unsurprising given that at higher deductible levels, any increase in that level affects a smaller and smaller fraction of total spending. 
There are other possible explanations for our findings. If there are statewide differences in the rate of adoption of high deductible plans related to statewide differences in responsiveness to coverage, there could be "(adverse) selection on moral hazard" (Einav et al., 2013). If so, the absence of a response to changes over time in deductibles would imply that less responsive (to cost-sharing) individuals were moving to higher deductible plans, which may or may not be a plausible story. Additionally, it is possible that other types of changes in plan generosity, such as increases in copayments/coinsurance rates or out-of-pocket maximums, might have a larger or stronger effect on the growth in spending. ${ }^{5}$ These changes may or may not be correlated with changes in deductibles.

While our aggregate market-level data have some distinct advantages over individual data (especially individual data from samples of convenience), there other limitations to our analysis. First, the simple specification of the empirical model means we may miss some potential nonlinearities or interaction effects of interest. Second, we cannot completely rule out endogeneity and establish a definitive causal relationship between deductibles and spending growth. We attempt to address the potential endogeneity of deductibles in multiple ways including IV estimation and inclusion of relevant covariates. For the IV analysis, we cannot establish that all of our instruments are unequivocally exogenous, and our necessarily subjective choice of multiple instruments raises the possibility of overidentification. Post-estimation tests of overidentifying restrictions indicate potential model misspecification and/or invalid instruments for models of growth in total, hospital and prescription drug spending, but not for models of growth in private benefits (our primary outcome). Model misspecification for spending outcomes that include spending on behalf of non-privately insured is possible, given a lack of economic theory to guide functional form in such cases. Additionally, it is possible that some bias remains in our OLS estimates from other unobserved characteristics that are both correlated with deductibles and predictive of spending growth.

It is important for future work to further explore the relationship between insurance coverage and spending growth at the market level. Such research should consider other features of plan benefit design such as those mentioned above, which may affect utilization and spending differently

\footnotetext{
${ }^{5}$ Additional measures of office visit copayments are also available within the MEPS IC. We do not use these measures in our main models as we think that relative to deductibles, office visit copays are more specific and limited in their ability to affect aggregate spending trends. Furthermore, we observe much less variation in such measures across states and over time.
} 
than deductibles. When relationships are identified, it is also important to identify the underlying behavioral mechanisms and whether they represent intended and/or socially beneficial responses. Any reduction in the use of care caused by high cost-sharing trades off benefits from the foregone care against lower insurance premiums. Research has shown that individuals respond to higher out-of-pocket costs by reducing care thought by clinicians to be of both low- and high-value, but with minimal impact on measured health outcomes (Brot-Goldberg et al., 2017; Newhouse, 1993). It is equally important for future work to examine the complementary role of supply-side costcontainment mechanisms, such as selective contracting/narrow networks, in influencing health care spending growth. The insurance industry and policy-makers who regulate it should consider our findings as important evidence in their ongoing efforts to understand the tradeoff between quality improvement and cost containment.

\section{References}

Brot-Goldberg, Z. C., Chandra, A., Handel, B. R., and Kolstad, J. T. (2017). What does a deductible do? The impact of cost-sharing on health care prices, quantities, and spending dynamics. The Quarterly Journal of Economics, 132(3):1261-1318.

Buchmueller, T. C., DiNardo, J., and Valletta, R. G. (2002). Union effects on health insurance provision and coverage in the United States. ILR Review, 55(4):610-627.

Bundorf, M. K. (2016). Consumer-directed health plans: A review of the evidence. Journal of Risk and Insurance, 83(1):9-41.

Chandra, A. and Skinner, J. (2012). Technology Growth and Expenditure Growth in Health Care. Journal of Economic Literature, 50(3):645-80.

Chernew, M. E. and Newhouse, J. P. (2011). Health Care Spending Growth. Handbook of Health Economics, 2:1-43.

Einav, L., Finkelstein, A., Ryan, S. P., Schrimpf, P., and Cullen, M. R. (2013). Selection on moral hazard in health insurance. American Economic Review, 103(1):178-219.

Finkelstein, A. (2007). The aggregate effects of health insurance: Evidence from the introduction of Medicare. The Quarterly Journal of Economics, 122(1):1-37.

Finkelstein, A., Taubman, S., Wright, B., Bernstein, M., Gruber, J., Newhouse, J. P., Allen, H., Baicker, K., and Group, O. H. S. (2012). The Oregon health insurance experiment: evidence from the first year. The Quarterly Journal of Economics, 127(3):1057-1106.

Golberstein, E., Walsh, K., He, Y., and Chernew, M. E. (2013). Supplemental coverage associated with more rapid spending growth for Medicare beneficiaries. Health Affairs, 32(5):873-881. 
Haviland, A. M., Eisenberg, M. D., Mehrotra, A., Huckfeldt, P. J., and Sood, N. (2016). Do "consumer-directed" health plans bend the cost curve over time? Journal of Health Economics, $46: 33-51$.

Kaiser Family Foundation (2014). 2014 Employer Health Benefits Survey. Technical report, Kaiser Family Foundation.

Keeler, E. B., Newhouse, J. P., and Phelps, C. E. (1977). Deductibles and the Demand for Medical Care Services: The Theory of a Consumer Facing a Variable Price Schedule under Uncertainty. Econometrica, 45(3):641-655.

Manning, W. G., Newhouse, J. P., Duan, N., Keeler, E. B., and Leibowitz, A. (1987). Health Insurance and the Demand for Medical Care: Evidence from a Randomized Experiment. The American Economic Review, 77(3):251-277.

Newhouse, J. P. (1978). The erosion of the medical marketplace. RAND Corporation, Santa Monica, CA.

Newhouse, J. P. (1988). Has the Erosion of the Medical Marketplace Ended? Journal of Health Politics Policy and Law, 13(2):263-278.

Newhouse, J. P. (1992). Medical Care Costs: How Much Welfare Loss? Journal of Economic Perspectives, 6(3):3-21.

Newhouse, J. P. (1993). An iconoclastic view of health cost containment. Health Affairs, 12(suppl 1):152-171.

Nyman, J. A. (1999). The value of health insurance: the access motive. Journal of Health Economics, 18(2):141-152.

Parente, S. T., Feldman, R., and Christianson, J. B. (2004a). Employee Choice of ConsumerDriven Health Insurance in a Multiplan, Multiproduct Setting. Health Services Research, 39(4p2):10911112 .

Parente, S. T., Feldman, R., and Christianson, J. B. (2004b). Evaluation of the effect of a consumerdriven health plan on medical care expenditures and utilization. Health Services Research, 39(4p2):1189-1210.

Pauly, M. V. (1968). The Economics of Moral Hazard : Comment. American Economic Review, $58(3): 531-537$.

Peden, E. A. and Freeland, M. S. (1998). Insurance effects on US medical spending (1960-1993). Health Economics, 7(8):671-687.

The Heritage Foundation (2006). Building on the Successes of Health Savings Accounts. Technical report, The Heritage Foundation.

Van de Ven, W. P. and Van Praag, B. M. (1981). The demand for deductibles in private health insurance. Journal of Econometrics, 17(2):229-252.

Weisbrod, B. A. (1991). The Health Care Quadrilemma: Essay on Technological Change, Insurance, Quality of Care, and Cost Containment. Journal of Economic Literature, 29(2):523-552. 


\section{Figures}

Figure 1: Spending Growth Following a Coverage Change

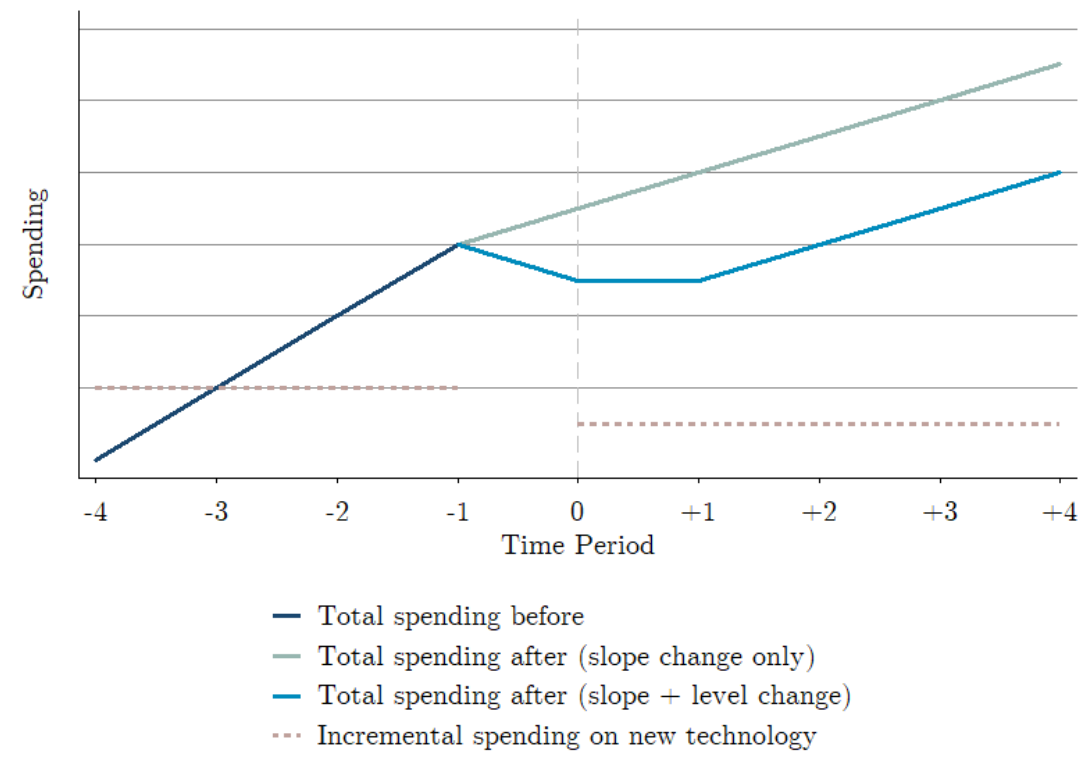

Figure 2: Deductibles among Privately Insured Employees from 2002-2016

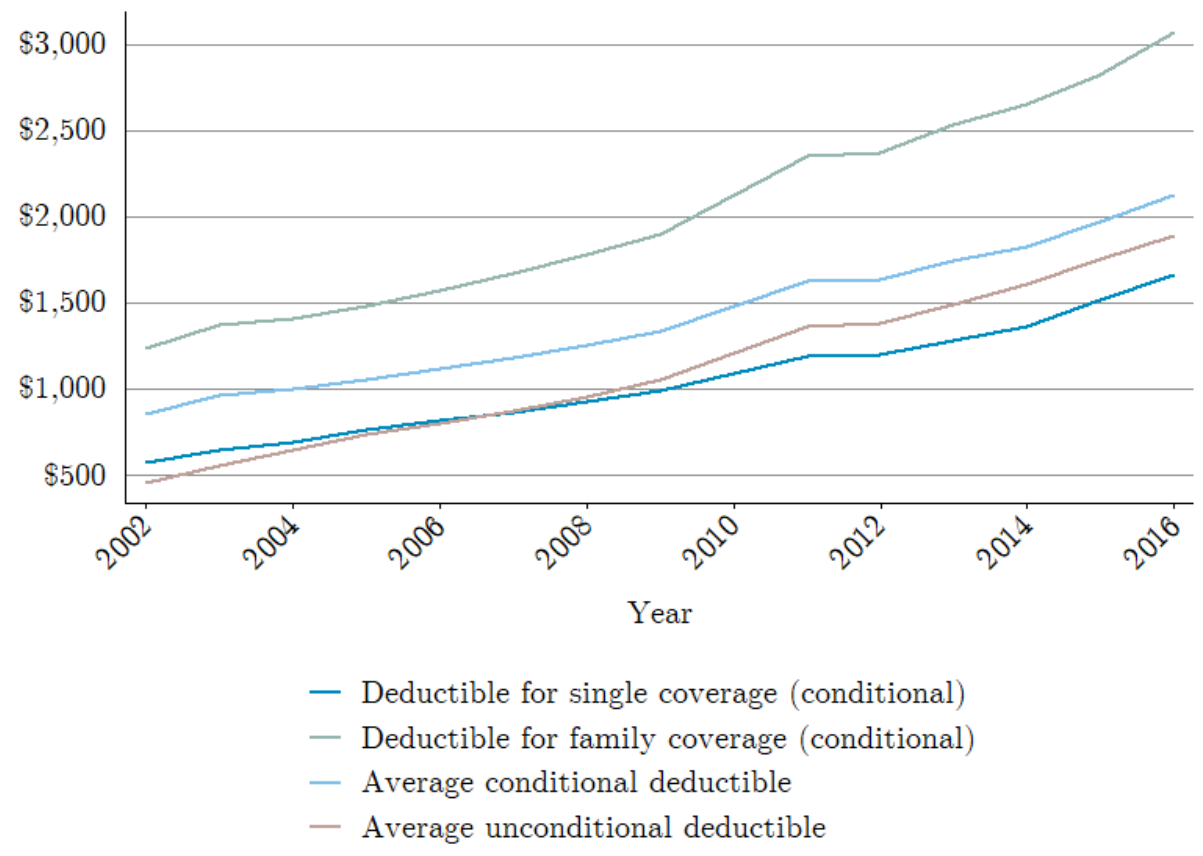


Figure 3: Health Care Spending from 2002-2014

Panel A. Total Spending per Capita and Benefits per Enrollee

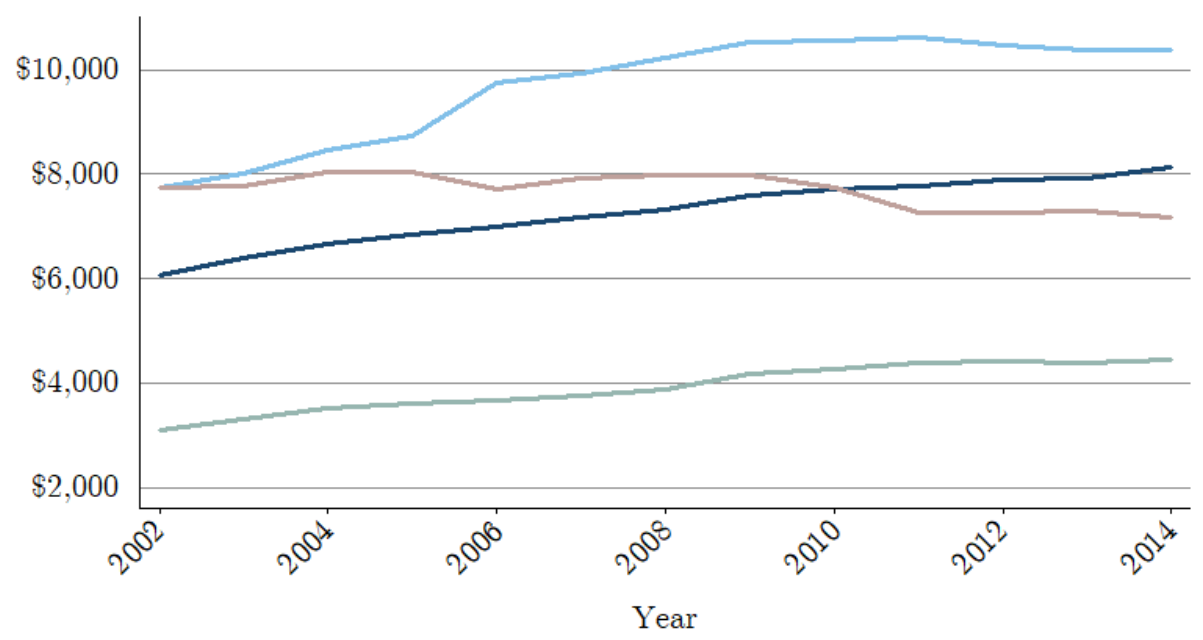

- Total spending per capita

- Private benefits per enrollee

- Medicare benefits per enrollee

- Medicaid benefits per enrollee

Panel B. Spending per Capita in Selected Settings

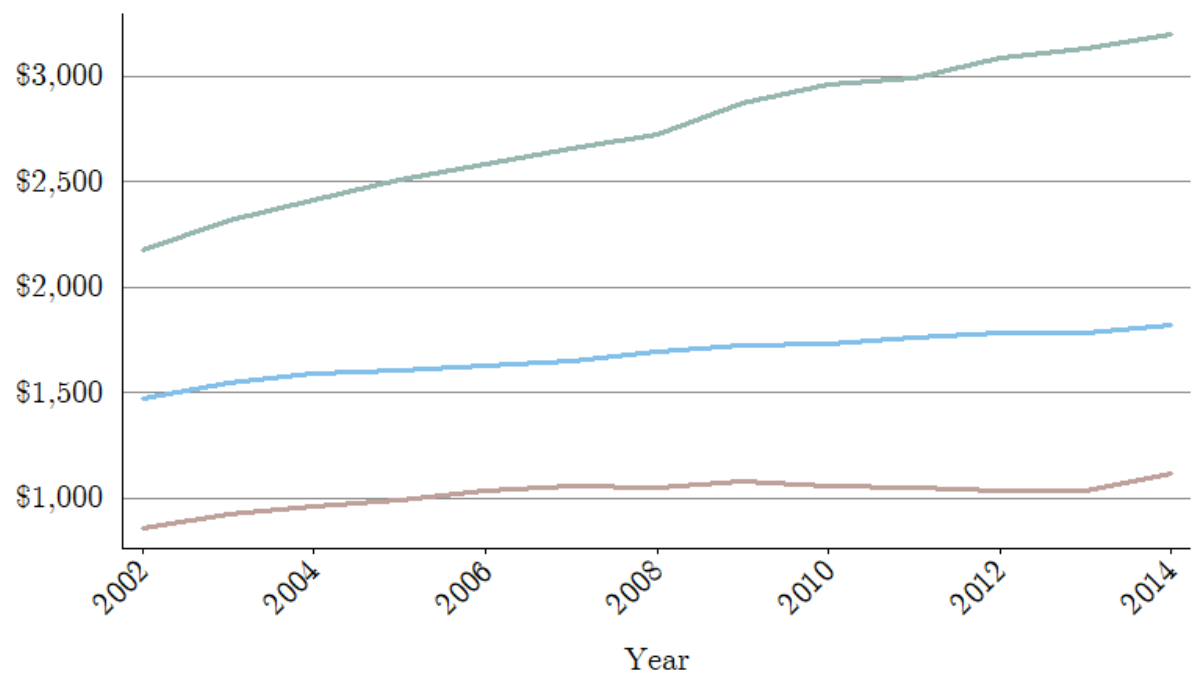

- Hospital Care

- Physician Services

- Prescription Drug 


\section{Tables}

Table 1: First Stage Model of Logged Average Deductible

\begin{tabular}{lc}
\hline \hline & $(1)$ \\
\hline Average firm size & $-0.0251^{*}$ \\
& $(0.0130)$ \\
Legislature share republican & $0.907^{* * *}$ \\
& $(0.244)$ \\
Proportion of workers unionized & $-4.831^{* * *}$ \\
& $(1.248)$ \\
Mean adult worker age & $0.182^{* * *}$ \\
& $(0.0164)$ \\
Constant & -0.627 \\
& $(0.806)$ \\
N & 537 \\
F & 0.486 \\
\hline \hline Standard errors in parentheses; ${ }^{*} p<0.10,{ }^{* *} p<0.05,{ }^{* * *} p<0.01$
\end{tabular}

Table 2: Growth in Total Spending and Private Benefits

\begin{tabular}{lcccc}
\hline \hline & \multicolumn{2}{c}{ Total } & \multicolumn{2}{c}{ Private } \\
& OLS & IV & OLS & IV \\
& $(1)$ & $(2)$ & $(3)$ & $(4)$ \\
\hline Average deductible level & $-0.0138^{* * *}$ & $-0.0127^{* * *}$ & $-0.0257^{* * *}$ & $-0.0219^{* * *}$ \\
& $(0.00265)$ & $(0.00301)$ & $(0.00358)$ & $(0.00459)$ \\
Average deductible percent change & $0.0119^{* *}$ & $0.0128^{* *}$ & 0.00163 & 0.00383 \\
& $(0.00485)$ & $(0.00517)$ & $(0.0223)$ & $(0.0229)$ \\
& & & & \\
Constant & $0.117^{* * *}$ & $0.109^{* * *}$ & $0.206^{* * *}$ & $0.179^{* * *}$ \\
& $(0.0186)$ & $(0.0209)$ & $(0.0258)$ & $(0.0329)$ \\
\hline $\mathrm{N}$ & 549 & 537 & 549 & 537 \\
$\mathrm{R}$-squared & 0.168 & 0.166 & 0.0575 & 0.0584 \\
\hline \hline Standard errors in parentheses; OLS $=$ ordinary least squares; IV $=$ instrumental variables; \\
${ }^{*} p<0.10,{ }^{* *} p<0.05,{ }^{* * *} p<0.01$
\end{tabular}


Table 3: Growth in Setting-Specific Spending

\begin{tabular}{lcccccc}
\hline \hline & \multicolumn{2}{c}{ Hospital Care } & \multicolumn{2}{c}{ Physician Services } & \multicolumn{2}{c}{ Prescription Drug } \\
& OLS & IV & OLS & IV & OLS & IV \\
& $(1)$ & $(2)$ & $(3)$ & $(4)$ & $(5)$ & $(6)$ \\
\hline Average deductible level & $-0.0114^{* * *}$ & $-0.00814^{* *}$ & $-0.0126^{* * *}$ & $-0.0105^{* * *}$ & $-0.0245^{* * *}$ & $-0.0219^{* * *}$ \\
& $(0.00338)$ & $(0.00394)$ & $(0.00275)$ & $(0.00306)$ & $(0.00284)$ & $(0.00412)$ \\
& & & & & & \\
Average deductible percent change & $0.0147^{* *}$ & $0.0173^{* *}$ & $0.0160^{*}$ & $0.0162^{* *}$ & 0.00486 & 0.00746 \\
& $(0.00729)$ & $(0.00784)$ & $(0.00805)$ & $(0.00816)$ & $(0.00941)$ & $(0.00947)$ \\
& & & & & & \\
Constant & $0.108^{* * *}$ & $0.0848^{* * *}$ & $0.102^{* * *}$ & $0.0875^{* * *}$ & $0.189^{* * *}$ & $0.170^{* * *}$ \\
& $(0.0237)$ & $(0.0271)$ & $(0.0194)$ & $(0.0212)$ & $(0.0200)$ & $(0.0288)$ \\
\hline $\mathrm{N}$ & 549 & 537 & 549 & 537 & 549 & 537 \\
R-squared & 0.0564 & 0.0519 & 0.0695 & 0.0687 & 0.0849 & 0.0858 \\
\hline \hline
\end{tabular}

Standard errors in parentheses; OLS $=$ ordinary least squares; IV $=$ instrumental variables; ${ }^{*} p<0.10,{ }^{* *} p<0.05,{ }^{* * *} p<0.01$

Table 4: Growth in Medicare and Medicaid Benefits

\begin{tabular}{lcccc}
\hline \hline & \multicolumn{2}{c}{ Medicare } & \multicolumn{2}{c}{ Medicaid } \\
& OLS & IV & OLS & IV \\
& $(1)$ & $(2)$ & $(3)$ & $(4)$ \\
\hline Average deductible level & $-0.0301^{* * *}$ & $-0.0342^{* * *}$ & $-0.0124^{* * *}$ & $-0.0169^{* * *}$ \\
& $(0.00574)$ & $(0.00635)$ & $(0.00431)$ & $(0.00634)$ \\
Average deductible percent change & 0.00175 & 0.000670 & -0.00906 & -0.0125 \\
& $(0.00899)$ & $(0.00878)$ & $(0.0306)$ & $(0.0304)$ \\
Constant & & & & \\
& $0.231^{* * *}$ & $0.259^{* * *}$ & $0.0810^{* *}$ & $0.112^{* *}$ \\
\hline $\mathrm{N}$ & $(0.0407)$ & $(0.0447)$ & $(0.0312)$ & $(0.0449)$ \\
$\mathrm{R}$-squared & 549 & 537 & 549 & 537 \\
\hline \hline
\end{tabular}

Standard errors in parentheses; OLS = ordinary least squares; IV = instrumental variables;

${ }^{*} p<0.10,{ }^{* *} p<0.05,{ }^{* * *} p<0.01$

Table 5: Growth in Employer-Sponsored Private Premiums

\begin{tabular}{|c|c|c|c|c|}
\hline & \multicolumn{2}{|c|}{ Percent Change } & \multicolumn{2}{|c|}{ Dollar Change } \\
\hline & OLS & IV & OLS & IV \\
\hline & $(1)$ & $(2)$ & $(3)$ & $(4)$ \\
\hline \multirow[t]{2}{*}{ Average deductible level } & $-0.0227^{* * *}$ & $-0.0149^{* * *}$ & $-13.72^{* * *}$ & $-7.357^{* * *}$ \\
\hline & $(0.00326)$ & $(0.00327)$ & $(1.527)$ & $(2.317)$ \\
\hline \multirow[t]{2}{*}{ Average deductible change } & -0.0122 & -0.00810 & $-25.27^{* *}$ & $-32.33^{* * *}$ \\
\hline & $(0.0137)$ & $(0.0140)$ & $(11.55)$ & $(11.40)$ \\
\hline \multirow[t]{2}{*}{ Constant } & $0.182^{* * *}$ & $0.128^{* * *}$ & $376.7^{* * *}$ & $309.6^{* * *}$ \\
\hline & $(0.0235)$ & $(0.0234)$ & $(20.78)$ & $(28.06)$ \\
\hline $\mathrm{N}$ & 641 & 627 & 641 & 627 \\
\hline R-squared & 0.0718 & 0.0635 & 0.0628 & 0.0553 \\
\hline
\end{tabular}




\section{Appendix Tables}

Table A1: Growth in Private Benefits, Private Out-of-Pocket Spending and Total Private Spending

\begin{tabular}{|c|c|c|c|c|c|c|}
\hline & \multicolumn{2}{|c|}{ Private Benefits } & \multicolumn{2}{|c|}{ Estimated Private OOP } & \multicolumn{2}{|c|}{ Estimated Total Private } \\
\hline & OLS & IV & OLS & IV & OLS & IV \\
\hline Average deductible level & $\begin{array}{c}(1) \\
-0.0257^{* * *} \\
(0.00358)\end{array}$ & $\begin{array}{c}(2) \\
-0.0219^{* * *} \\
(0.00459)\end{array}$ & $\begin{array}{c}(3) \\
-0.00943 \\
(0.00636)\end{array}$ & $\begin{array}{c}(4) \\
-0.0139^{* *} \\
(0.00669)\end{array}$ & $\begin{array}{c}(5) \\
-0.0194^{* * *} \\
(0.00327)\end{array}$ & $\begin{array}{c}(b) \\
-0.0193^{* * *} \\
(0.00382)\end{array}$ \\
\hline Average deductible percent change & $\begin{array}{c}0.00163 \\
(0.0223)\end{array}$ & $\begin{array}{c}0.00383 \\
(0.0229)\end{array}$ & $\begin{array}{c}0.0860^{* *} \\
(0.0380)\end{array}$ & $\begin{array}{l}0.0844^{* *} \\
(0.0375)\end{array}$ & $\begin{array}{c}0.0310^{* * *} \\
(0.0112)\end{array}$ & $\begin{array}{c}0.0314^{* * *} \\
(0.0117)\end{array}$ \\
\hline Constant & $\begin{array}{l}0.206^{* * *} \\
(0.0258) \\
\end{array}$ & $\begin{array}{l}0.179^{* * *} \\
(0.0329) \\
\end{array}$ & $\begin{array}{c}0.0818^{*} \\
(0.0441) \\
\end{array}$ & $\begin{array}{c}0.112^{* *} \\
(0.0458) \\
\end{array}$ & $\begin{array}{l}0.158^{* * *} \\
(0.0223) \\
\end{array}$ & $\begin{array}{l}0.157^{* * *} \\
(0.0261) \\
\end{array}$ \\
\hline $\mathrm{N}$ & 549 & 537 & 549 & 537 & 549 & 537 \\
\hline R-squared & 0.0575 & 0.0584 & 0.0210 & 0.0210 & 0.0997 & 0.101 \\
\hline
\end{tabular}

Table A2: Growth in Hospital Spending, Admissions and Spending per Admission

\begin{tabular}{|c|c|c|c|c|c|c|}
\hline & \multicolumn{2}{|c|}{ Hospital Spending Per Capita } & \multicolumn{2}{|c|}{ Admissions Per Capita } & \multicolumn{2}{|c|}{ Spending Per Admission } \\
\hline & OLS & IV & OLS & IV & OLS & IV \\
\hline & $(1)$ & $(2)$ & $(3)$ & $(4)$ & $(5)$ & $(6)$ \\
\hline \multirow[t]{2}{*}{ Average deductible level } & $-0.0114^{* * *}$ & $-0.00814^{* *}$ & $-0.00921^{* * *}$ & $-0.0101^{* * *}$ & -0.00222 & 0.00215 \\
\hline & $(0.00338)$ & $(0.00394)$ & $(0.00312)$ & $(0.00375)$ & $(0.00227)$ & $(0.00440)$ \\
\hline \multirow[t]{2}{*}{ Average deductible percent change } & $0.0147^{* *}$ & $0.0173^{* *}$ & 0.0113 & 0.0115 & 0.00347 & 0.00595 \\
\hline & $(0.00729)$ & $(0.00784)$ & $(0.00841)$ & $(0.00848)$ & $(0.0117)$ & $(0.0128)$ \\
\hline \multirow[t]{2}{*}{ Constant } & $0.108^{* * *}$ & $0.0848^{* * *}$ & $0.0702^{* * *}$ & $0.0762^{* * *}$ & $0.0375^{* *}$ & 0.00736 \\
\hline & $(0.0237)$ & $(0.0271)$ & $(0.0223)$ & $(0.0266)$ & $(0.0160)$ & $(0.0309)$ \\
\hline $\mathrm{N}$ & 549 & 537 & 549 & 537 & 549 & 537 \\
\hline R-squared & 0.0564 & 0.0519 & 0.0228 & 0.0224 & 0.00126 & . \\
\hline
\end{tabular}


Table A3: Growth in Private Benefits: OLS with Additional Controls and State Fixed Effects

\begin{tabular}{lccccc}
\hline \hline & $(1)$ & $(2)$ & $(3)$ & $(4)$ & $(5)$ \\
\hline Average deductible level & $-0.0216^{* * *}$ & $-0.0232^{* * *}$ & $-0.0269^{* * *}$ & $-0.0411^{* * *}$ & $-0.0270^{* *}$ \\
& $(0.00389)$ & $(0.00334)$ & $(0.00422)$ & $(0.00417)$ & $(0.0124)$ \\
Average deductible percent change & 0.00369 & -0.00277 & 0.0101 & 0.00162 & 0.000593 \\
& $(0.0255)$ & $(0.0225)$ & $(0.0275)$ & $(0.0234)$ & $(0.0307)$ \\
Constant & & & & & \\
& $0.261^{*}$ & $0.198^{* * *}$ & $0.216^{* * *}$ & $0.311^{* * *}$ & 0.403 \\
& $(0.146)$ & $(0.0232)$ & $(0.0292)$ & $(0.0298)$ & $(0.425)$
\end{tabular}

Additional Controls

\begin{tabular}{lccccc} 
Insurance coverage & Yes & No & No & No & Yes \\
Medicare Advantage penetration & No & Yes & No & No & Yes \\
Hospital market concentration & No & No & Yes & No & Yes \\
State fixed effects & No & No & No & Yes & Yes \\
N & 457 & 549 & 537 & 549 & 447 \\
R-squared & 0.107 & 0.0705 & 0.0621 & 0.0886 & 0.144 \\
\hline \hline
\end{tabular}

Standard errors in parentheses; OLS $=$ ordinary least squares; ${ }^{*} p<0.10,{ }^{* *} p<0.05,{ }^{* * *} p<0.01$

Table A4: Growth in Private Benefits: IV with Additional Controls and State Fixed Effects

\begin{tabular}{|c|c|c|c|c|c|}
\hline & $(1)$ & $(2)$ & $(3)$ & $(4)$ & $(5)$ \\
\hline Average deductible level & $\begin{array}{l}-0.0144^{* *} \\
(0.00646)\end{array}$ & $\begin{array}{c}-0.0213^{* * *} \\
(0.00436)\end{array}$ & $\begin{array}{c}-0.0225^{* * *} \\
(0.00646)\end{array}$ & $\begin{array}{c}-0.0401^{* * *} \\
(0.00554)\end{array}$ & $\begin{array}{c}0.0422 \\
(0.0419)\end{array}$ \\
\hline Average deductible percent change & $\begin{array}{l}0.00676 \\
(0.0257)\end{array}$ & $\begin{array}{r}-0.00218 \\
(0.0228)\end{array}$ & $\begin{array}{c}0.0128 \\
(0.0280)\end{array}$ & $\begin{array}{l}0.00189 \\
(0.0232)\end{array}$ & $\begin{array}{l}-0.0207 \\
(0.0369)\end{array}$ \\
\hline Constant & $\begin{array}{l}0.230^{*} \\
(0.121)\end{array}$ & $\begin{array}{l}0.186^{* * *} \\
(0.0306)\end{array}$ & $\begin{array}{l}0.187^{* * *} \\
(0.0433)\end{array}$ & $\begin{array}{l}0.304^{* * *} \\
(0.0384)\end{array}$ & $\begin{array}{c}0.132 \\
(0.412)\end{array}$ \\
\hline \multicolumn{6}{|l|}{ Additional Controls } \\
\hline Insurance coverage & Yes & No & No & No & Yes \\
\hline Medicare Advantage penetration & No & Yes & No & No & Yes \\
\hline Hospital market concentration & No & No & Yes & No & Yes \\
\hline State fixed effects & No & No & No & Yes & Yes \\
\hline $\mathrm{N}$ & 447 & 537 & 525 & 537 & 437 \\
\hline R-squared & 0.103 & 0.0732 & 0.0622 & 0.0597 & 0.0101 \\
\hline
\end{tabular}


Table A5: Growth in Total Spending: OLS with Additional Controls and State Fixed Effects

\begin{tabular}{lccccc}
\hline \hline & $(1)$ & $(2)$ & $(3)$ & $(4)$ & $(5)$ \\
\hline Average deductible level & $-0.0137^{* * *}$ & $-0.0124^{* * *}$ & $-0.0180^{* * *}$ & $-0.0238^{* * *}$ & $-0.0253^{* * *}$ \\
& $(0.00276)$ & $(0.00206)$ & $(0.00149)$ & $(0.00170)$ & $(0.00494)$ \\
Average deductible percent change & $0.0129^{* *}$ & $0.0102^{* *}$ & $0.0130^{* *}$ & $0.0134^{* * *}$ & $0.0129^{*}$ \\
& $(0.00555)$ & $(0.00477)$ & $(0.00632)$ & $(0.00470)$ & $(0.00712)$ \\
Constant & 0.114 & $0.114^{* * *}$ & $0.138^{* * *}$ & $0.186^{* * *}$ & $0.370^{* * *}$ \\
& $(0.126)$ & $(0.0136)$ & $(0.0103)$ & $(0.0118)$ & $(0.127)$ \\
Additional Controls & & & & & No \\
Insurance coverage & Yes & No & No & Yes \\
Medicare Advantage penetration & No & Yes & No & No & Yes \\
Hospital market concentration & No & No & Yes & No & Yes \\
State fixed effects & No & No & No & Yes & Yes \\
\hline N & 457 & 549 & 537 & 549 & 447 \\
R-squared & 0.224 & 0.213 & 0.232 & 0.295 & 0.414 \\
\hline \hline
\end{tabular}

Standard errors in parentheses; OLS $=$ ordinary least squares; ${ }^{*} p<0.10,{ }^{* *} p<0.05,{ }^{* * *} p<0.01$

Table A6: Growth in Total Spending: IV with Additional Controls and State Fixed Effects

\begin{tabular}{lccccc}
\hline \hline & $(1)$ & $(2)$ & $(3)$ & $(4)$ & $(5)$ \\
\hline Average deductible level & $-0.00986^{* *}$ & $-0.0125^{* * *}$ & $-0.0187^{* * *}$ & $-0.0254^{* * *}$ & $-0.0301^{* * *}$ \\
& $(0.00417)$ & $(0.00231)$ & $(0.00303)$ & $(0.00229)$ & $(0.0104)$ \\
Average deductible percent change & $0.0147^{* *}$ & $0.0102^{* *}$ & $0.0128^{*}$ & $0.0129^{* * *}$ & $0.0149^{*}$ \\
& $(0.00581)$ & $(0.00498)$ & $(0.00681)$ & $(0.00498)$ & $(0.00797)$ \\
Constant & 0.0930 & $0.115^{* * *}$ & $0.142^{* * *}$ & $0.196^{* * *}$ & $0.379^{* * *}$ \\
& $(0.101)$ & $(0.0152)$ & $(0.0202)$ & $(0.0160)$ & $(0.126)$ \\
Additional Controls & & & & & No \\
Insurance coverage & Yes & No & No & Yes \\
Medicare Advantage penetration & No & Yes & No & No & Yes \\
Hospital market concentration & No & No & Yes & No & Yes \\
State fixed effects & No & No & No & Yes & Yes \\
\hline N & 447 & 537 & 525 & 537 & 437 \\
R-squared & 0.216 & 0.210 & 0.230 & 0.1651 & 0.1682 \\
\hline \hline
\end{tabular}

Standard errors in parentheses; IV $=$ instrumental variables; ${ }^{*} p<0.10,{ }^{* *} p<0.05,{ }^{* * *} p<0.01$ 
Table A7: Growth in Total Spending and Benefits by Payer (Dollar Differences)

\begin{tabular}{|c|c|c|c|c|c|c|c|c|}
\hline & \multicolumn{2}{|c|}{ Total } & \multicolumn{2}{|c|}{ Private } & \multicolumn{2}{|c|}{ Medicare } & \multicolumn{2}{|c|}{ Medicaid } \\
\hline & $\begin{array}{l}\text { OLS } \\
(1)\end{array}$ & $\begin{array}{l}\text { IV } \\
(2)\end{array}$ & $\begin{array}{l}\text { OLS } \\
(3)\end{array}$ & $\begin{array}{l}\text { IV } \\
(4)\end{array}$ & $\begin{array}{l}\text { OLS } \\
(5)\end{array}$ & $\begin{array}{l}\text { IV } \\
(6)\end{array}$ & $\begin{array}{c}\text { OLS } \\
(7)\end{array}$ & $\begin{array}{l}\text { IV } \\
(8)\end{array}$ \\
\hline Average deductible level & $\begin{array}{c}-9.770^{* * *} \\
(1.446)\end{array}$ & $\begin{array}{c}-9.376^{* * *} \\
(2.207)\end{array}$ & $\begin{array}{c}-9.551^{* * *} \\
(1.428)\end{array}$ & $\begin{array}{c}-8.622^{* * *} \\
(1.685)\end{array}$ & $\begin{array}{c}-35.58^{* * *} \\
(3.476)\end{array}$ & $\begin{array}{c}-38.74^{* * *} \\
(4.879)\end{array}$ & $\begin{array}{l}-6.059 \\
(4.503)\end{array}$ & $\begin{array}{c}-12.34^{* *} \\
(6.265)\end{array}$ \\
\hline Average deductible dollar change & $\begin{array}{c}4.851 \\
(4.576)\end{array}$ & $\begin{array}{c}4.694 \\
(4.502)\end{array}$ & $\begin{array}{c}6.316 \\
(9.654)\end{array}$ & $\begin{array}{c}5.289 \\
(9.485)\end{array}$ & $\begin{array}{l}16.41^{*} \\
(8.375)\end{array}$ & $\begin{array}{l}20.68^{* *} \\
(8.861)\end{array}$ & $\begin{array}{l}-24.93 \\
(27.37)\end{array}$ & $\begin{array}{l}-19.45 \\
(28.30)\end{array}$ \\
\hline Constant & $\begin{array}{c}268.5^{* * *} \\
(17.46)\end{array}$ & $\begin{array}{c}263.7^{* * *} \\
(22.12)\end{array}$ & $\begin{array}{c}205.3^{* * *} \\
(14.41)\end{array}$ & $\begin{array}{c}196.2^{* * *} \\
(18.02) \\
\end{array}$ & $\begin{array}{c}580.2^{* * *} \\
(44.83)\end{array}$ & $\begin{array}{c}606.8^{* * *} \\
(55.75) \\
\end{array}$ & $\begin{array}{c}35.52 \\
(52.47) \\
\end{array}$ & $\begin{array}{c}95.04 \\
(65.78) \\
\end{array}$ \\
\hline $\mathrm{N}$ & 549 & 537 & 549 & 537 & 549 & 537 & 549 & 537 \\
\hline R-squared & 0.118 & 0.116 & 0.0426 & 0.0439 & 0.224 & 0.222 & 0.00698 & 0.00384 \\
\hline
\end{tabular}

Table A8: Growth in Total Spending by Setting (Dollar Differences)

\begin{tabular}{lcccccc}
\hline \hline & \multicolumn{3}{c}{ Hospital Care } & \multicolumn{2}{c}{ Physician Services } & \multicolumn{2}{c}{ Prescription Drug } \\
& OLS & IV & OLS & IV & OLS & IV \\
& $(1)$ & $(2)$ & $(3)$ & $(4)$ & $(5)$ & $(6)$ \\
\hline Average deductible level & $-2.520^{* * *}$ & -1.390 & $-2.303^{* * *}$ & $-2.007^{* * *}$ & $-1.919^{* * *}$ & $-2.285^{* * *}$ \\
& $(0.874)$ & $(1.282)$ & $(0.364)$ & $(0.534)$ & $(0.280)$ & $(0.479)$ \\
Average deductible dollar change & 3.421 & 2.824 & 1.458 & 0.819 & -0.937 & -0.490 \\
& $(2.571)$ & $(2.443)$ & $(1.444)$ & $(1.380)$ & $(1.210)$ & $(1.293)$ \\
& & & & \\
Constant & $106.6^{* * *}$ & $95.17^{* * *}$ & $51.99^{* * *}$ & $49.16^{* * *}$ & $42.59^{* * *}$ & $45.63^{* * *}$ \\
& $(10.11)$ & $(12.64)$ & $(4.117)$ & $(5.201)$ & $(3.449)$ & $(5.093)$ \\
\hline $\mathrm{N}$ & 549 & 537 & 549 & 537 & 549 & 537 \\
R-squared & 0.0229 & 0.0178 & 0.0538 & 0.0532 & 0.0442 & 0.0444 \\
\hline \hline Standard errors in parentheses; OLS $=$ ordinary least squares; IV $=$ instrumental variables; ${ }^{*} p<0.10,{ }^{* *} p<0.05,,^{* * *} p<0.01$
\end{tabular}

